\title{
Development of a noninvasive photograph-based method for the evaluation of body condition in free-ranging brown bears
}

\author{
Yuri Shirane ${ }^{1}$, Fumihiko Mori ${ }^{1}$, Masami Yamanaka ${ }^{2}$, Masanao Nakanishi ${ }^{2}$, Tsuyoshi Ishinazaka ${ }^{2}$, Tsutomu Mano \\ , Mina Jimbo ${ }^{1}$, Mariko Sashika ${ }^{1}$, Toshio Tsubota $^{1}{ }^{1}$, Michito Shimozuru ${ }^{\text {Corresp. } 1}$ \\ ${ }^{1}$ Graduate School of Veterinary Medicine, Hokkaido University, Sapporo, Hokkaido, Japan \\ 2 Shiretoko Nature Foundation, Shari, Hokkaido, Japan \\ 3 Hokkaido Research Organization, Sapporo, Hokkaido, Japan \\ Corresponding Author: Michito Shimozuru \\ Email address: shimozuru@vetmed.hokudai.ac.jp
}

Body condition is an important determinant of health, and its evaluation has practical applications for the conservation and management of mammals. We developed a noninvasive method that uses photographs to assess the body condition of free-ranging brown bears (Ursus arctos) in the Shiretoko Peninsula, Hokkaido, Japan. First, we weighed and measured 476 bears captured during 1998-2017 and calculated their body condition index $(\mathrm{BCl})$ based on residuals from the regression of body mass against body length. $\mathrm{BCl}$ showed seasonal changes and was lower in spring and summer than in autumn. The torso height:body length ratio was strongly correlated with $\mathrm{BCl}$, which suggests that it can be used as an indicator of body condition. Second, we examined the precision of photographbased measurements using an identifiable bear in the Rusha area, a special wildlife protection area on the peninsula. A total of 220 lateral photographs of this bear were taken September 24-26, 2017, and classified according to bear posture. The torso height:body/torso length ratio was calculated with four measurement methods and compared among bear postures in the photographs. The results showed torso height:horizontal torso length (TH:HTL) to be the indicator that could be applied to photographs of the most diverse postures, and its coefficient of variation for measurements was $<5 \%$. In addition, when analyzing photographs of this bear taken from June to October during 2016-2018, TH:HTL was significantly higher in autumn than in spring/summer, which indicates that this ratio reflects seasonal changes in body condition in wild bears. Third, we calculated $\mathrm{BCl}$ from actual measurements of seven females captured in the Rusha area and TH:HTL from photographs of the same individuals. We found a significant positive relationship between $\mathrm{TH}: \mathrm{HTL}$ and $\mathrm{BCl}$, which suggests that the body condition of brown bears can be estimated with high accuracy based on photographs. Our simple and accurate method is useful for monitoring bear body condition repeatedly 
over the years and contributes to further investigation of the relationships among body condition, food habits, and reproductive success. 


\section{Development of a noninvasive photograph-based}

\section{2 method for the evaluation of body condition in free-}

\section{3 ranging brown bears}

6 Yuri Shirane ${ }^{1}$, Fumihiko Mori ${ }^{1}$, Masami Yamanaka ${ }^{2}$, Masanao Nakanishi², Tsuyoshi

7 Ishinazaka ${ }^{2}$, Tsutomu Mano ${ }^{3}$, Mina Jimbo ${ }^{1}$, Mariko Sashika ${ }^{1}$, Toshio Tsubota ${ }^{1}$, and Michito

8 Shimozuru $^{1}$

9

$10{ }^{1}$ Graduate School of Veterinary Medicine, Hokkaido University, Sapporo, Hokkaido, Japan

$11{ }^{2}$ Shiretoko Nature Foundation, Shari, Hokkaido, Japan

$12{ }^{3}$ Hokkaido Research Organization, Sapporo, Hokkaido, Japan

14 Corresponding Author:

15 Michito Shimozuru

16

17 Email address: shimozuru@vetmed.hokudai.ac.jp 


\section{Abstract}

22

Body condition is an important determinant of health, and its evaluation has practical applications for the conservation and management of mammals. We developed a noninvasive method that uses photographs to assess the body condition of free-ranging brown bears (Ursus arctos) in the Shiretoko Peninsula, Hokkaido, Japan. First, we weighed and measured 476 bears captured during 1998-2017 and calculated their body condition index (BCI) based on residuals from the regression of body mass against body length. BCI showed seasonal changes and was lower in spring and summer than in autumn. The torso height:body length ratio was strongly correlated with BCI, which suggests that it can be used as an indicator of body condition. Second, we examined the precision of photograph-based measurements using an identifiable bear in the Rusha area, a special wildlife protection area on the peninsula. A total of 220 lateral photographs of this bear were taken September 24-26, 2017, and classified according to bear posture. The torso height:body/torso length ratio was calculated with four measurement methods and compared among bear postures in the photographs. The results showed torso height:horizontal torso length (TH:HTL) to be the indicator that could be applied to photographs of the most diverse postures, and its coefficient of variation for measurements was $<5 \%$. In addition, when analyzing photographs of this bear taken from June to October during 20162018, TH:HTL was significantly higher in autumn than in spring/summer, which indicates that this ratio reflects seasonal changes in body condition in wild bears. Third, we calculated BCI from actual measurements of seven females captured in the Rusha area and TH:HTL from photographs of the same individuals. We found a significant positive relationship between TH:HTL and BCI, which suggests that the body condition of brown bears can be estimated with high accuracy based on photographs. Our simple and accurate method is useful for monitoring 
44 bear body condition repeatedly over the years and contributes to further investigation of the 45 relationships among body condition, food habits, and reproductive success.

46 


\section{Introduction}

48 Body condition, defined as the energetic state in an individual, especially the relative size

49 of energy reserves such as fat and protein (Gosler, 1996; Schulte-Hostedde, Millar \& Hickling,

50 2001; Peig \& Green, 2009), is an important determinant of health in both terrestrial and marine

51 mammals. It serves as an indicator of food quality (Mahoney, Virgl \& Mawhinney, 2001;

52 McLellan, 2011), reproductive success (Noyce \& Garshelis, 1994; Guinet et al., 1998), and

53 survivorship (Young, 1976; Gaillard et al., 2000). Animals in good body condition generally

54 have more energy reserves and are therefore more resilient and more likely to survive than those

55 in poorer condition (Cook et al., 2004; Clutton-Brock \& Sheldon, 2010). In females,

56 reproductive traits such as litter mass, number of litters, neonatal mass, and breeding life-span

57 increase with body condition (Samson \& Huot, 1995; Atkinson \& Ramsay, 1995). Therefore,

58 evaluating body condition is of general biological interest but also has practical applications for

59 the conservation and management of mammals.

60 The body condition of living mammals has been assessed with morphometric

61 measurements (Guinet et al., 1998; Cattet et al., 2002), blood analyses (Hellgren, Rogers \& Seal,

62 1993; Gau \& Case, 1999), bioelectrical impedance (Farley \& Robbins, 1994; Hilderbrand, Farley

$63 \&$ Robbins, 1998), and ultrasound measurements of subcutaneous fat (Morfeld et al., 2014).

64 However, these methods are unsuitable as a routine method because they require repeated

65 capture of individuals. Applying these methods to free-ranging, large-bodied mammals is

66 inherently difficult because the capture operation is dangerous for researchers and may affect

67 animal behavior and survival through anesthesia and direct handling. An alternative, noninvasive

68 evaluation method is body condition scoring (BCS). BCS is a subjective assessment of

69 subcutaneous body fat stores based on a visual or tactile evaluation of muscle tone and key 
70 skeletal elements (Otto et al., 1991; Burkholder, 2000). Various BCS systems have been

71 established for monitoring individual condition in companion animals (e.g., dogs and cats:

72 Laflamme, 2012), livestock (e.g., cattle, horses, and pigs: Wildman et al., 1982; Henneke et al.,

73 1983; Department for Environment Food and Rural Affairs, 2004), and also wildlife (e.g., bears,

74 dolphins, and elephants: Stirling, Thiemann \& Richardson, 2008; Morfeld et al., 2014; Joblon et

75 al., 2015). In addition, visual assessment criteria based on photographs have been used to

76 evaluate relative body condition in whales. Photograph-based measurements of the length and

77 width of gray whales (Eschrichtius robustus) from vertical aerial photogrammetry can reveal

78 changes in body condition associated with fasting during winter migrations (Perryman \& Lynn,

79 2002). These studies demonstrate that it is possible to visually detect changes in body condition

80 without capturing animals.

81 For killed or captured bears (Ursus spp.), a body condition index (BCI) has been

82 established based on residuals from the regression of body mass against straight-line body length

83 (i.e., the observed mass minus the expected mass: Cattet et al., 2002). Independently of sex or

84 age, the BCI has a strong positive relationship with true body condition, defined as the combined

85 mass of fat and skeletal muscle relative to body size (Atkinson, Nelson \& Ramsay, 1996; Cattet

86 et al., 2002). The BCI has higher positive values for bears in better condition and lower negative

87 values for those in poorer condition. In addition, predictive equations have been developed to

88 estimate body mass and condition in bears from measurements of straight-line body length and

89 axillary girth (Bartareau, 2017; Moriwaki et al., 2018). However, to clarify seasonal and annual

90 changes in the body condition of bears, it is necessary to develop a method that can be used to

91 monitor body condition repeatedly and continued for several years. For proper conservation and 
92 management of bear populations, it is important to develop a noninvasive method of assessing

93 body condition in bears without capture operations.

94 In this study, we developed a noninvasive method of evaluating the body condition of

95 brown bears (Ursus arctos) based on morphometric measurements obtained from photographs.

96 Brown bears are large omnivores that can change their diet in response to spatial and seasonal

97 variation in food resources (Bojarska \& Selva, 2012) and have a wide distribution throughout the

98 Northern Hemisphere. In Japan, they occur only on Hokkaido, the northernmost island of the

99 country (Fig. 1). Our goal was to develop an accurate, photograph-based evaluation method that

100 could be applied to bears in various postures. To achieve this, we took the following three steps.

101 First, we conducted preliminary analyses using BCIs calculated from actual measurements of

102 killed or captured bears to obtain fundamental information on the body condition of Hokkaido

103 brown bears. We also investigated whether the ratio of torso height to body length could be used

104 as an indicator of body condition by examining its correlation with BCI. Second, we validated

105 the precision of photograph-based measurements using photographs of an identifiable female.

106 We identified four candidate methods of measurement, including horizontal body length,

107 Euclidean body length, polygonal-line body length, and horizontal torso length. Then, we

108 examined which method had the largest number of applicable photographs with sufficiently

109 small variation in measurement. We also examined the ability of our method to detect seasonal

110 changes in body condition. Third, we validated the accuracy of the photograph-based

111 measurement method by examining the correlation between BCIs calculated from actual

112 measurements of captured individuals and photographic evaluation of the same individuals.

\section{Materials \& Methods}




\section{Study area}

116 This study was conducted in the Shiretoko Peninsula $\left(43^{\circ} 50^{\prime}-44^{\circ} 20^{\prime} \mathrm{N}, 144^{\circ} 45^{\prime}-145^{\circ} 20^{\prime}\right.$

117 E), Hokkaido, Japan (Fig. 1). This peninsula has one of the largest brown bear populations

118 worldwide (Hokkaido Government, 2017), and an area from the middle to the tip of the

119 peninsula has been designated as Shiretoko National Park and a UNESCO World Natural

120 Heritage Site. During 1998-2017, we collected body masses and morphometrics from brown

121 bears captured for research purposes, killed for nuisance control, or harvested from the

122 peninsula, including the towns of Shari and Rausu (Fig. 1). In addition, a focal survey was

123 conducted in the Rusha area $\left(44^{\circ} 12^{\prime} \mathrm{N}, 145^{\circ} 12^{\prime}\right.$ E; Fig. 1), a special wildlife protection area.

124 Public access is not allowed without permission and there is no human residence except for one

125 fishermen's settlement. Because the fishermen have not excluded bears from the settlement area

126 in the last few decades, the bears have become habituated to the existence of humans, which

127 enables direct observation at close range. Long-term monitoring of identifiable bears has been

128 conducted in this region since 2006 (Shimozuru et al., 2017). We collected body masses,

129 morphometrics, and photographs of female bears in the Rusha area during 2014-2016. Field

130 experiments were approved by Hokkaido Regional Environment Office and Kushiro Nature

131 Conservation Office (Permit Number: 1606091 and 1705182).

\section{Bear capture and measurements}

Bears were sampled each year during 1998-2017 between April and November. Most samples were obtained from bears killed for nuisance control or harvested, and some were

136 obtained from bears captured for research purposes. The variables recorded for each bear

137 included an identification code, date of measurement, location, body mass (kg), and straight-line 
138 body length $(\mathrm{cm})$ (Supplemental Data S1). Body mass was measured with calibrated hanging

139 spring scales. Body length was measured with a non-stretchable tape measure as the straight-line

140 distance from the tip of the nose to the end of the last tail vertebra while the bear was aligned

141 laterally. In addition, we measured torso height $(\mathrm{cm})$ as the distance from the lowest point of the

142 abdomen to the spine in females $\geq 5$ years old during 2014-2017. We also collected tissue (e.g.,

143 muscle and liver) from killed bears and blood and hair samples from captured bears for DNA

144 extraction, which allowed us to identify individuals and their sex (Shimozuru et al., 2017;

145 Shirane et al., 2018). Among 503 killed or captured individuals, 22 individuals were sampled

146 more than once during our study period due to repeated capture or killing after capture; we used

147 only the measurement taken at the greatest age in the following analyses.

148 We estimated the age in years of most bears captured or killed by counting the cementum

149 annuli of the teeth (Yoneda, 1976). For some individuals, we could not determine the exact age

150 due to many cementum-layers developed in old individuals or poor quality of teeth samples.

151 Individuals whose age range could only be estimated were excluded from the growth curve

152 analyses but were included for BCI and subsequent analyses if the growth curve results (detailed

153 below) allowed their classification into an age class. For example, females $\geq 5$ years old were

154 excluded from growth curve analyses but were used as adults for subsequent analyses, whereas

155 males $\geq 5$ years old were excluded from all analyses.

156 All bears were captured live in accordance with the Guidelines for Animal Care and Use

157 of Hokkaido University and all procedures were approved by the Animal Care and Use

158 Committee of the Graduate School of Veterinary Medicine, Hokkaido University (Permit

159 Number: 1152 and 15009). The protocols for capture received annual approval from the Ministry

160 of the Environment, Japan, and the Hokkaido Government through research permit applications. 


\section{Growth curve of body length}

163 To estimate the age at which the growth of body length was completed, growth pattern in

164 body length was examined using a von Bertalanffy curve as previously described in bears

165 (Kingsley, Nagy \& Reynolds, 1988; Derocher \& Stirling, 1998; Derocher \& Wiig, 2002;

166 Bartareau, Cluff \& Larter, 2011). The von Bertalanffy size-at-age equation was used in the form

$167 \mathrm{~A}_{\mathrm{t}}=\mathrm{A}_{\infty}\left(1-\mathrm{e}^{-\mathrm{K}(\mathrm{t}-\mathrm{T})}\right)$, where $\mathrm{A}_{\mathrm{t}}$ is body length (in $\mathrm{cm}$ ) at age $\mathrm{t}, \mathrm{A}_{\infty}$ is asymptotic body length (in

$168 \mathrm{~cm}), \mathrm{K}$ is a size growth rate constant $\left(\right.$ year $^{-1}$ ), and $\mathrm{T}$ is a fitting constant (extrapolated age at zero

169 size; in years). We conducted F tests to determine whether the parameters of the von Bertalanffy

170 growth equation differed significantly by sex. We conducted analyses using FSA package

171 version 0.8 .30 (Ogle, Wheeler \& Dinno, 2020) and nlstools package version 1.0-2 (Baty et al.,

172 2015) in $\mathrm{R}$ (R Core Team, 2019). According to the age reaching 95\% of the asymptotic body

173 lengths obtained from this analysis (detailed below), bears were assigned to three age classes for

174 each sex: cubs (0-1 years old), subadults (age 1-4 years and 1-7 years for females and males,

175 respectively), and adults (age $\geq 5$ years and $\geq 8$ years for females and males, respectively).

\section{$177 \mathrm{BCl}$ of killed or captured bears}

178 We calculated BCI as previously described in Cattet et al. (2002). Specifically, body

179 mass and length values were transformed to natural logarithms and a least-squares linear

180 regression analysis was conducted to describe the relationship between the ln-transformed

181 values. The standardized residuals of this linear regression were used as BCI. In addition, as a

182 preliminary experiment for the evaluation of body condition using photographs, we calculated

183 the ratio of torso height to body length (TH:BL) using actual measurement data. 

investigated the correlation between BCI and body length that is an indicator of body size

186 (Mahoney, Virgl \& Mawhinney, 2001; Cattet et al., 2002). BCI was compared among seasons 187 and age-sex classes using two-way analysis of variance (ANOVA). We used Tukey multiple comparisons (Tukey, 1977) to evaluate differences between the mean values of each comparison. Based on major changes in diet (Ohdachi \& Aoi, 1987), we divided the sampling period into three seasons: spring (April to June; main diet of grass), summer (July and August; main diet of

191 grass and ants), and autumn (September to November; main diet of berries and acorns). In

192 addition, we linearly regressed BCI on the TH:BL of the same individuals and calculated the correlation coefficient. We also used correlation analysis between TH:BL and body length to investigate the effects of body size. We conducted all statistical analyses in R (R Core Team, 195 2019).

\section{Obtaining and filtering of photographs}

Periodic surveys ( $\geq 1$ day/2 weeks) have been conducted since 2011 in the Rusha area, mainly for monitoring the reproductive status of identifiable females (Shimozuru et al., 2017). This area is a narrow estuarine coast stretching south to north for approximately $3 \mathrm{~km}$. Field teams patrolled the area by car and waited for bears to emerge from the vegetation on the mountainside. When bears appeared, we followed individuals, maintaining a distance of about 20-100 m. Individual bears were identified by field staff according to their appearance as described in Shimozuru et al. (2017), and close-up photographs were taken from multiple angles with a digital, single-lens reflex camera (Nikon D800, NIKON Co., Tokyo, Japan; or Canon 

selected and graded based on several attributes: camera focus, camera tilt (vertical), camera angle (horizontal), body/torso height measurability, and body/torso length measurability for

210 photography; and degree of body arch (vertical), straightness of body (horizontal), degree of

211 neck flexing (vertical), and degree of neck bending (horizontal) for bear posture (Table S1, Fig.

212 S1). Each photograph was given a score of 1 (good quality), 2 (medium quality), or 3 (poor

213 quality) for each attribute. Photographs that were given a score of 3 for any attribute were

214 removed from further analyses.

215

\section{Morphometric measurements from photographs}

We used ImageJ version 1.52a (Schneider, Rasband \& Eliceiri, 2012) to extract

morphometric measurements from lateral photographs of bears. We first adjusted the angle of the

photographs according to the ground surface, then measured the torso height in pixels (TH) as the distance perpendicular to the ground from the lowest point of the abdomen to the highest point of the waist (Fig. 2). Length measurements (in pixels) included the following four methods: the horizontal straight-line body length (HBL, Fig. 2) was the straight-line distance from the tip of the nose to the base of the tail; the Euclidean straight-line body length (EBL, Fig. 2) was the Euclidean distance from the base of the tail to tip of the nose; the polygonal-line body length (PBL, Fig. 2) was the sum of the distance from the base of the tail to the highest part of the shoulder parallel to the ground surface, from that point to the base of the ear, and from that point to the tip of the nose; and the horizontal straight-line torso length (HTL, Fig. 2) was the straight-

228 line distance from the base of the tail to the highest part of the shoulder parallel to the ground. 
229 For all measurements, any area that could be clearly judged to be only fur was excluded from the 230 measurement range.

\section{Precision of measurements from photographs}

To examine the precision of each photograph-based measurement method and the effects

234 of bear posture, we used photographs of one bear (bear ID: HC) that was monitored routinely in 235 the Rusha area during 2016-2018. We classified photographs according to bear posture (Table

236 S1 and Fig. S1): photographs that had a score of 1 for all attributes were assigned to "Good",

237 those with a score of 2 for body straightness only were assigned to "BS", those with a score of 2

238 for neck flexing only were assigned to "NF", and those with a score of 2 for neck lateral bending 239 only were assigned to "NB". Photographs that were not assigned to any category were excluded 240 from these analyses.

241 First, to determine the number of measurements sufficient to reduce measurement error, 242 we assessed measurement precision within photographs by repeatedly measuring (50 times) the

243 body morphometrics from the best photograph taken on September 25, 2017, and assigned to the

244 "Good" category. From these measurements, the coefficients of variation (CVs) for TH, HBL,

245 EBL, PBL, HTL, and the ratio of TH to body/torso length were calculated. In addition, by

246 considering the standard deviation obtained from the 50 measurements as the population

247 standard deviation, we calculated the measurement error at a given number of measurements. We 248 ultimately adopted the minimum number of measurements for which the measurement error had 249 a value that did not affect the second decimal place (i.e., $<0.0025$ ). In the following analyses, $\mathrm{TH}$ 250 and body/torso length were measured three times, and the TH:body/torso length ratio was

251 calculated from the respective average values according to our results (detailed below). 

repeated measures of the same individual taken from photographs with different postures) by taking measurements from photographs in different posture categories. To eliminate the effects of seasonal changes in body condition, we restricted these analyses to photographs taken September 24-26, 2017. The TH:body/torso length ratio was compared among the posture categories for each measurement method with one-way ANOVA. We used Tukey multiple comparisons (Tukey, 1977) to evaluate differences between the mean values of different categories. Then we calculated the $\mathrm{CV}$ of each method using all of the photographs applicable to the method to evaluate the measurement precision of each method. We compared CVs among the four methods using an asymptotic test (Feltz \& Miller, 1996). From these results, we adopted

262 the method that could be applied to photographs of the most diverse postures while maintaining a 263 sufficiently high measurement precision between photographs $(\mathrm{CV}<5 \%)$. In accordance with 264 these results (detailed below), we used TH:HTL as an indicator of body condition in the 265 following analyses. Third, to examine whether TH:HTL reflected seasonal changes in body condition, we used photographs taken between late June and early October during 2016-2018. For each halfmonth, the best two or more photographs were selected and the median TH:HTL obtained from these photographs was considered the evaluation value for that half-month. We compared TH:HTL among half-months using one-way ANOVA and used Tukey multiple comparisons

271 (Tukey, 1977) to evaluate differences between the mean values of each half-month. We 272 conducted statistical analyses using Microsoft Excel ${ }^{\circledR}$ (Microsoft Corporation, 2016) or R (R 273 Core Team, 2019). 
275 Accuracy of measurements from photographs

276 We examined the accuracy of photograph-based measurement methods using actual

277 measurement data for seven females ( $\geq 5$ years old) captured in the Rusha area (bear IDs: BE,

278 DR, GI, KR, LI, RI, and WK). We collected photographs of these individuals from within 3 days

279 before and after the days the individuals were captured. After filtering the photographs, we

280 measured TH and HTL and calculated the TH:HTL ratio using two or more of the best

281 photographs. We also calculated BCI using the body mass and length measured at the time of 282 capture.

283 Statistical methods. - We linearly regressed BCI on the TH:HTL ratio and calculated

284 the correlation coefficient. We conducted statistical analyses using Microsoft Excel ${ }^{\circledR}$ (Microsoft

285 Corporation, 2016).

286

287

\section{Results}

We weighed and measured 503 different individuals: 9 females from the Rusha area 289 during 2014-2016 and 494 individuals (201 females and 293 males) from other parts of the

Shiretoko Peninsula during 1998-2017. Among these, we assigned an age (in years) to 432 individuals (174 females and 258 males) and an age range to 56 individuals.

292

293

\section{Body length growth curves}

von Bertalanffy curves were successfully fitted to body length data for the 432

individuals with age (in years) assignments (Fig. 3, Table 1, Data S1). The growth curves asymptotic body length at 4.6 years of age, whereas males took 7.6 years to reach the same 
298 proportion. In accordance with these results, 476 individuals, including those with known age

299 ranges, were classified into age classes and used in the subsequent analyses: 8 females and 19

300 males were cubs, 105 females (1-4 years) and 211 males (1-7 years) were subadults, and 92

301 females $\geq 5$ years old and 41 males $\geq 8$ years old were adults.

302

\section{$303 \mathrm{BCl}$ of killed or captured bears}

304 Natural logarithmic transformation of the body mass and length data resulted in a linear

305 relationship between mass and length as follows: $\ln$ body mass $=3.04 \cdot \ln$ body length -10.40

$306\left(\mathrm{R}^{2}=0.94\right.$, residual standard deviation $=0.19$, Fig. 4 , Data $\left.\mathrm{S} 1\right)$. To facilitate estimation of BCI

307 for brown bears, we developed the following model: $\mathrm{BCI}=$ (ln body mass $-3.04 \ln$ body length

$308+10.40) / 0.19$. There was no correlation between body length and BCI $(r=0.037, p=0.39)$,

309 which indicates that BCI was independent of body size (Fig. S2).

310 An ANOVA of BCI showed that BCI varied significantly by season $\left(F_{2,459}=13.26, p<\right.$

311 0.001; Table 2, Fig. 5), with bears sampled in spring and summer having lower BCI than bears

312 sampled in autumn (both $p<0.001$ ). Differences among age-sex classes were also significant

$313\left(F_{5,459}=4.20, p<0.001\right)$ : Adult males showed higher BCI than adult females $(p=0.002)$,

314 subadult females $(p<0.001)$, and subadult males $(p=0.003)$, whereas BCI did not differ among

315 other age-sex classes $(p=0.35-0.99)$. The interaction between season and age-sex class was not

316 significant $\left(F_{9,459}=0.46, p=0.90\right)$.

317 We obtained measurements of torso height from 23 adult females. A positive correlation

318 was found between the TH:BL ratio and $\mathrm{BCI}(r=0.81, p<0.001$; Fig. 6 , Data S1). There was no

319 correlation between body length and TH:BL $(r=-0.068, p=0.73)$, which indicates that TH:BL

320 was independent of body size (Fig. S3). 


\section{Precision of measurements from photographs}

A total of 220 photographs of the same bear (bear ID: HC) were taken September 24-26,

324

325 2017. After filtering based on photographic conditions and the body arch of the bear (Table S1 and Fig. S1), 101 photographs remained. Of these photographs, 15 were assigned to "Good," 9 to "BS," 10 to "NF," and 9 to "NB."

Based on 50 repeat measurements of the best photograph in the "Good" category, the CV in measurement error within photographs was estimated to be $0.29 \%$ for torso height and $0.27 \%$, $0.29 \%, 0.26 \%$, and $0.45 \%$ for HBL, EBL, PBL, and HTL, respectively. For all measurement methods, we reduced the measurement error of the ratio of height to length to less than \pm 0.0025 by measuring height and body/torso length $\geq 3$ times (Table 3 ).

The torso height:body/torso length ratio differed among the posture categories for all measurement methods $(p<0.001$ for TH:HBL and TH:EBL, $p=0.005$ for TH:PBL, and $p=$ 0.002 for TH:HTL, Table 4, Data S2). TH:HBL and TH:EBL obtained from photographs in the "BS," "NF," and "NB" categories differed significantly from the results obtained from photographs in the "Good" category (Table 4). TH:PBL measured using "BS" and "NB" photographs were different from those of "Good" photographs (Table 4). TH:HTL differed from "Good" photographs only when we used "BS" photographs (Table 4). When we used all photographs in each category that did not differ from "Good" for each method, the CV was $<5 \%$ for all methods and did not differ among methods ( $p=0.067): 2.47 \%$ in TH:HBL (photo $n=15$ ), 2.19\% in TH:EBL $(n=15), 3.18 \%$ in TH:PBL $(n=25)$, and 3.93\% in TH:HTL $(n=34)$. Given these results, TH:HTL was adopted as the measurement method with both the largest number of applicable photographs and a $\mathrm{CV}<5 \%$ (i.e., high measurement precision between photographs). 

late June to early October during 2016-2018, we determined that TH:HTL reached its lowest in

346 late August $(0.567 \pm 0.012$; mean $\pm \mathrm{SE})$ and its highest in early October $(0.714 \pm 0.015$, Fig. 7$)$.

347 TH:HTL varied significantly among half-months $\left(F_{7,16}=18.41, p<0.001\right)$ and was lower in 348 early August than in late June $(p=0.013)$, early July $(p=0.007)$, late July $(p=0.012)$, early

349 September $(p<0.001)$, late September $(p<0.001)$, or early October $(p<0.001)$.

\section{Accuracy of measurements from photographs}

We captured seven adult females in the Rusha area during 2014-2016 and took

353 photographs of each individual within 3 days before and after each capture date (Table S2).

354 There was a positive correlation between BCI calculated from actual morphometric 355 measurements and TH:HTL calculated from photographs $(r=0.78, p=0.041$; Fig. 8).

\section{Discussion}

We have developed a new method for visually assessing the body condition of adult

359 female brown bears using photographs. The evaluation method consists of filtering photographs

360 based on photograph conditions and bear posture and using photograph-based measurements of 361 torso height and horizontal torso length in pixels to calculate the TH:HTL ratio. The significant 362 positive relationship between TH:HTL calculated from photographs and BCI calculated from 363 actual measurements of given individuals indicates that the body condition of brown bears can be 364 estimated with a high degree of accuracy based on photographs. TH:HTL values increased as 365 BCI increased, in agreement with other body condition indices, such as Quetelet's index (Cattet, 
366 2000) and percent body fat (McLellan, 2011). This study is the first to propose a photograph-

367 based method of evaluating bear body condition that is accurate and reliable.

368 The most versatile photograph-based measurement method that could be applied to bears

369 with various postures was the measurement not of body length but of torso length. In right

370 whales (Eubalaena sp.) and gray whales, body condition has been evaluated with high precision

371 and accuracy with aerial vehicle photogrammetry by selecting photographs under strict

372 conditions based on the whale's posture (Perryman \& Lynn, 2002; Christiansen et al., 2018).

373 However, it is not easy to collect a large number of good-quality photographs of brown bears

374 inhabiting forests that are suitable for measurement. In fact, of the 220 photographs taken to

375 confirm the precision of photograph-based measurement methods in this study, only 15 (6.8\%)

376 were classified into the "Good" category. Therefore, to establish a useful method of assessing

377 body condition, it was necessary to find a method that had high applicability as well as high

378 precision and accuracy. Although the body length of killed or captured brown bears is generally

379 measured as the distance from the tip of the nose to the end of the last tail vertebra (Blanchard,

380 1987), in the present study all methods that included the tip of the nose in the photograph-based

381 measurement range (i.e., HBL, EBL, and PBL) were affected by the degree of neck flexing and

382 neck lateral bending. However, the torso length (i.e., HTL) could be measured without being

383 affected by the condition of the neck as long as the condition of body straightness was satisfied.

384 TH:HTL declined from June to August and increased thereafter until the end of the field

385 survey in early October, which suggests that bears were gaining fat over this period. The period

386 when TH:HTL was lowest (i.e., August) coincides with the time when most cub disappearances

387 occur in the Rusha area (Shimozuru et al., 2017), which indicates that poor nutrition in the

388 summer may cause cub mortality. The seasonal changes in TH:HTL were partly consistent with 
389 BCIs calculated from killed bears, except that TH:HTL increased drastically in September.

390 Because seasonal changes in TH:HTL were examined in only one individual in this study, it is

391 necessary to examine how TH:HTL changes seasonally in other living bears. One factor leading

392 to the difference between seasonal change patterns in TH:HTL and BCI may be differences in

393 the food environment between the Rusha area and other areas. Acorns (Quercus crispula), which

394 contain large quantities of carbohydrates and fats, are a major food source throughout Hokkaido

395 during September-November (Ohdachi \& Aoi, 1987; Sato, Mano \& Takatsuki, 2005). In

396 addition, the Rusha area is considered to be a natural "ecocenter", defined by Craighead, Sumner

$397 \&$ Mitchell (1995) as an area where highly nutritional food is concentrated during a certain part

398 of the year, and many bears are present in this area to obtain these resources, in particular

399 salmonid fish, from late August (Yamanaka \& Aoi, 1988; Shimozuru et al., 2017). Therefore,

400 bears in the Rusha area can consume higher-energy foods from late summer to autumn, which

401 may cause their TH:HTL to increase more rapidly than the BCI of bears killed in other areas.

402 Another possible explanation for the difference in seasonal change patterns of body condition is

403 that most of the actual measurements were collected from bears killed for nuisance control.

404 Throughout the lower part of the peninsula, vast agricultural farms produce mainly dent corn and

405 sugar beets. These farms may act as an attractive sink because of the availability of human-

406 derived foods, which lead to human-caused bear deaths (Delibes, Gaona \& Ferreras, 2001; Sato

407 et al., 2011). Therefore, there is a possibility that bears killed before September included those

408 that had emerged into farmland or human residential areas to obtain anthropogenic foods to

409 compensate for poor body condition. Our results suggest that including body condition data for

410 living bears will improve estimations of seasonal and long-term trends in body condition and

411 thus provide better estimates of the health of the bear population. 
412 It is important to determine whether the method established using adult females in this

413 study can be extended to other age-sex classes, other bear populations, and other bear species.

414 Differences in body condition among age-sex classes should be taken into consideration. Our

415 results showed that BCIs calculated from actual measurements were higher in adult males than in

416 other age-sex classes. Therefore, relative changes in TH:HTL need to be examined by age-sex

417 class. This study also showed no interaction between age-sex classes and seasons for BCI, which

418 indicates that any age-sex class would show similar seasonal changes in body condition.

419 However, it is necessary to investigate further whether the TH:HTL of other age-sex classes is

420 able to show the seasonal changes that can be detected in adult females. Another consideration is

421 differences in growth patterns between populations. Asymptotic body length $(\mathrm{cm})$ was smaller in

422 the Shiretoko Peninsula, $145.07 \pm 1.48$ and $179.47 \pm 2.39$ for females and males, respectively,

423 than in two previously studied brown bear populations in northern Canada (171.55 \pm 1.15 and

$424197.05 \pm 0.69$, Bartareau et al. 2011) and Alaska (166.10-194.08 and 190.72-206.36,

425 Hilderbrand et al., 2018). Therefore, when using our photograph-based method to evaluate body

426 condition in other populations, it is necessary to select target individuals depending on the age of

427 maturity in each population.

428 Because the equipment needed to weigh large-bodied animals is often inadequate or

429 unavailable in the field, it is more difficult to directly measure the body mass of brown bears

430 than it is to take other morphometric measurements. The TH:BL ratio measured from killed or

431 captured bears in this study was strongly correlated with BCI, which suggests that TH:BL, as

432 well as axillary girth, which allows us to estimate body mass (Cattet, 1990; Derocher \& Wiig,

433 2002; Cattet \& Obbard, 2005; Bartareau, 2017; Moriwaki et al., 2018), can be considered a

434 useful indicator of body condition in captured bears without direct measurement of body mass. 
435 In mice, pelvic circumference is considered a potential predictor of fat content (Labocha, Schutz

$436 \&$ Hayes, 2014). In addition, abdominal girth has been widely used in measurements of humans

437 (e.g., as part of calculating body mass index). Although torso height is a nonstandard

438 morphometric measurement in bear studies, such additional data may make it possible to

439 improve predictions of body condition. Furthermore, using our photograph-based method, we

440 can overcome the technical and financial difficulties of repeated capture and can conduct

441 periodic assessments of body condition. A noninvasive evaluation method, BCS has been

442 previously described for polar bears (Ursus maritimus) (Stirling, Thiemann \& Richardson,

443 2008). However, BCS is a subjective assessment system and has the disadvantage of potentially

444 missing small changes because it uses a scale from 1 to 5 . Using morphometric measurements

445 from photographs, our method makes it possible to conduct objective and quantitative visual

446 assessments of body condition and allows researchers to identify small fluctuations in body

447 condition. In this study, we were able to obtain usable photographs by conducting a survey in the

448 Rusha area, where we could photograph bears easily and safely. If automated trail cameras were

449 installed to collect bear photographs, our noninvasive assessment method of body condition

450 could be used widely in various locations.

\section{Conclusions}

We developed a noninvasive method that uses photographs to assess the body condition

of free-ranging brown bears and validated its accuracy against actual measurements of captured

455 bears in the Shiretoko Peninsula, Hokkaido, Japan. Because our method is simple and applicable

457 monitoring the body condition of brown bears repeatedly over the years. Using photograph- 
458 based evaluation will assist bear researchers in further investigating relationships among body

459 condition, food habit, and reproductive success, which contribute to the conservation and

460 management of brown bears.

461

\section{Acknowledgements}

We thank H. Ose and all the fishermen engaged in salmon fishing in the Rusha area for

their generous support. We are grateful to all the members of the Shiretoko Nature Foundation

465 for their generous support. We thank all the people involved in sample collection.

466

467

\section{References}

468

469

470

471

472

473

474

475

476

477

478

479

Atkinson SN, Nelson RA, Ramsay MA. 1996. Changes in the body composition of fasting polar bears (Ursus maritimus): The effect of relative fatness on protein conservation. Physiological Zoology 69:304-316. DOI: 10.2307/30164186.

Atkinson SN, Ramsay MA. 1995. The effects of prolonged fasting of the body composition and reproductive success of female Polar Bears (Ursus maritimus). Functional Ecology 9:559567. DOI: $10.2307 / 2390145$.

Bartareau TM. 2017. Estimating the live body weight of American black bears in Florida. Journal of Fish and Wildlife Management 8:234-239. DOI: 10.3996/012016-JFWM-003.

Bartareau TM, Cluff HD, Larter NC. 2011. Body length and mass growth of the brown bear (Ursus arctos) in northern Canada: Model selection based on information theory and ontogeny of sexual size dimorphism. Canadian Journal of Zoology 89:1128-1135. DOI: 10.1139/z11-088. 
480 Baty F, Ritz C, Charles S, Brutsche M, Flandrois J-P, Delignette-Muller M-L. 2015. A toolbox

481 for nonlinear regression in R: The package nlstools. Journal of Statistical Software 66:1-21.

482 DOI: $10.18637 /$ jss.v066.i05.

483 Blanchard BM. 1987. Size and growth patterns of the Yellowstone grizzly bear. Bears: Their

484 Biology and Management 7:99-107. DOI: 10.2307/3872615.

485 Bojarska K, Selva N. 2012. Spatial patterns in brown bear Ursus arctos diet: The role of

486 geographical and environmental factors. Mammal Review 42:120-143. DOI:

487 10.1111/j.1365-2907.2011.00192.x.

488

489

490

491

492

493

494

495

496

497

498

499

500

501

Burkholder WJ. 2000. Use of body condition scores in clinical assessment of the provision of optimal nutrition. Journal of the American Veterinary Medical Association 217:650-654. DOI: $10.2460 /$ javma.2000.217.650.

Cattet MRL. 1990. Predicting nutritional condition in black bears and polar bears on the basis of morphological and physiological measurements. Canadian Journal of Zoology 68:32-39. DOI: $10.1139 / \mathrm{z} 90-006$.

Cattet MRL. 2000. Biochemical and physiological aspects of obesity, high fat diet, and prolonged fasting in free-ranging polar bears. Ph.D. thesis, University of Saskatchewan, Saskatoon, Canada.

Cattet MRL, Caulkett NA, Obbard ME, Stenhouse GB. 2002. A body-condition index for ursids. Canadian Journal of Zoology 80:1156-1161. DOI: 10.1139/z02-103.

Cattet MRL, Obbard ME. 2005. To weigh or not to weigh: conditions for the estimation of body mass by morphometry. Ursus 16:102-107. DOI: 10.2192/15376176(2005)016[0102:TWONTW]2.0.CO;2. 
502 Christiansen F, Vivier F, Charlton C, Ward R, Amerson A, Burnell S, Bejder L. 2018. Maternal

503 body size and condition determine calf growth rates in southern right whales. Marine

504 Ecology Progress Series 592:267-281. DOI: 10.3354/meps12522.

505 Clutton-Brock T, Sheldon BC. 2010. Individuals and populations: The role of long-term,

506 individual-based studies of animals in ecology and evolutionary biology. Trends in Ecology

$507 \quad$ and Evolution 25:562-573. DOI: 10.1016/j.tree.2010.08.002.

508 Cook JG, Johnson BK, Cook RC, Riggs RA, Delcurto T, Bryant LD, Irwin LL. 2004. Effects of

509 summer-autumn nutrition and parturition date on reproduction and survival of elk. Wildlife

510 Monographs 155:1-61. DOI: 10.2193/0084-0173(2004)155[1:EOSNAP]2.0.CO;2.

511 Craighead JJ, Sumner JS, Mitchell JA. 1995. The grizzly bears of Yellowstone : their ecology in

512 the Yellowstone ecosystem, 1959-1992. Washington DC, USA: Island Press.

513 Delibes M, Gaona P, Ferreras P. 2001. Effects of an attractive sink leading into maladaptive

514 habitat selection. The American Naturalist 158:277-285. DOI: 10.1086/321319.

515 Department for Environment Food and Rural Affairs. 2004.Pigs: Condition Scoring (PB3480) -

$516 \quad$ How to Condition Score. Available at

517 http://adlib.everysite.co.uk/adlib/defra/content.aspx?id=000IL3890W.185EBLT3WHE457

518 (accessed August 11, 2020).

519 Derocher AE, Stirling I. 1998. Maternal investment and factors affecting offspring size in polar

520 bears (Ursus maritimus). Journal of Zoology 245:253-260. DOI: 10.1111/j.1469-

$521 \quad$ 7998.1998.tb00099.x.

522 Derocher AE, Wiig Ø. 2002. Postnatal growth in body length and mass of polar bears (Ursus

523 maritimus) at Svalbard. Journal of Zoology 256:S0952836902000377. DOI:

$524 \quad 10.1017 / \mathrm{S} 0952836902000377$. 
525 Farley SD, Robbins CT. 1994. Development of two methods to estimate body composition of

526 bears. Canadian Journal of Zoology 72:220-226. DOI: 10.1139/z94-029.

527 Feltz CJ, Miller GE. 1996. An asymptotic test for the equality of coefficients of variation from k

528 populations. Statistics in medicine 15:647-658. DOI: 10.1002/(SICI)1097-

529 0258(19960330)15:6<647::AID-SIM184>3.0.CO;2-P.

530 Gaillard J-M, Festa-Bianchet M, Yoccoz NG, Loison A, Toïgo C. 2000. Temporal variation in 531 fitness components and population dynamics of large herbivores. Annual Review of Ecology 532 and Systematics 31:367-393. DOI: 10.1146/annurev.ecolsys.31.1.367.

533 Gau RJ, Case R. 1999. Evaluating nutritional condition of grizzly bears via select blood 534 parameters. The Journal of Wildlife Management 63:286. DOI: 10.2307/3802511.

535 Gosler AG. 1996. Environmental and social determinants of winter fat storage in the great git 536 Parus major. The Journal of Animal Ecology 65:1-17. DOI: 10.2307/5695.

537 Guinet C, Roux JP, Bonnet M, Mison V. 1998. Effect of body size, body mass, and body 538 condition on reproduction of female South African fur seals (Arctocephalus pusillus) in 539 Namibia. Canadian Journal of Zoology 76:1418-1424. DOI: 10.1139/z98-082.

540 Hellgren EC, Rogers LL, Seal US. 1993. Serum chemistry and hematology of black bears:

541 physiological indices of habitat quality or seasonal patterns? Journal of Mammalogy

$542 \quad 74: 304-315$. DOI: $10.2307 / 1382385$.

543 Henneke DR, Potter GD, Kreider JL, Yeates BF. 1983. Relationship between condition score, 544 physical measurements and body fat percentage in mares. Equine Veterinary Journal 545 15:371-372. DOI: 10.1111/j.2042-3306.1983.tb01826.x.

546 Hilderbrand G V., Farley SD, Robbins CT. 1998. Predicting body condition of bears via two 547 field methods. The Journal of Wildlife Management 62:406-409. DOI: 10.2307/3802306. 
548 Hilderbrand G V., Gustine DD, Mangipane BA, Joly K, Leacock W, Mangipane LS, Erlenbach

549 J, Sorum MS, Cameron MD, Belant JL, Cambier T. 2018. Body size and lean mass of

550 brown bears across and within four diverse ecosystems. Journal of Zoology 305:53-62.

$551 \quad$ DOI: $10.1111 /$ jzo.12536.

552 Hokkaido Government. 2017.Brown bear management plan in Hokkaido. Available at

553 http://www.pref.hokkaido.lg.jp/ks/skn/higuma/hokkaido_bear_management_plan05.pdf(in

$554 \quad$ Japanese) (accessed December 8, 2017).

555 Joblon MJ, Pokras MA, Morse BJ, Harry CT, Rose KS, Sharp SM, Niemeyer ME, Patchett K,

556 Sharp WB, Moore MJ. 2015. Body condition scoring system for delphinids based on short-

557 beaked common dolphins (Delphinus delphis). Journal of Marine Animals and Their

$558 \quad$ Ecology 7:5-13.

559 Kingsley MCS, Nagy JA, Reynolds H V. 1988. Growth in length and weight of northern brown

560 bears: differences between sexes and populations. Canadian Journal of Zoology 66:981-

561 986. DOI: $10.1139 / \mathrm{z} 88-145$.

562 Labocha MK, Schutz H, Hayes JP. 2014. Which body condition index is best? Oikos 123:111-

563 119. DOI: $10.1111 / \mathrm{j} .1600-0706.2013 .00755 . x$.

564 Laflamme DP. 2012. Companion animals symposium: obesity in dogs and cats: what is wrong 565 with being fat? Journal of Animal Science 90:1653-1662. DOI: 10.2527/jas.2011-4571.

566 Mahoney SP, Virgl JA, Mawhinney K. 2001. Potential mechanisms of phenotypic divergence in 567 body size between Newfoundland and mainland black bear populations. Canadian Journal 568 of Zoology 79:1650-1660. DOI: 10.1139/z01-122. 
569 McLellan BN. 2011. Implications of a high-energy and low-protein diet on the body

570 composition, fitness, and competitive abilities of black (Ursus americanus) and grizzly

571 (Ursus arctos) bears. Canadian Journal of Zoology 89:546-558. DOI: 10.1139/z11-026.

572 Microsoft Corporation. 2016.Microsoft Excel. Available at https://office.microsoft.com/excel

573 Morfeld KA, Lehnhardt J, Alligood C, Bolling J, Brown JL. 2014. Development of a body

574 condition scoring index for female African elephants validated by ultrasound measurements

575 of subcutaneous fat. PLoS ONE 9:e93802. DOI: 10.1371/journal.pone.0093802.

576 Moriwaki J, Omori R, Shimozuru M, Tsuruga H, Mano T, Tsubota T. 2018. Evaluation of body

577 condition using body mass and chest girth in brown bears of Hokkaido, Japan (Ursus arctos

578 yesoensis). Japanese Journal of Veterinary Research 66:71-81. DOI: 10.14943/jjvr.66.2.71.

579 Noyce K V, Garshelis DL. 1994. Body size and blood characteristics as indicators of condition

580 and reproductive performance in black bears. Bears: Their Biology and Management

$581 \quad 9: 481-496$. DOI: $10.2307 / 3872736$.

582 Ogle DH, Wheeler P, Dinno A. 2020.FSA: Fisheries Stock Analysis. R package version 0.8.30.

583 Available at https://github.com/droglenc/FSA (accessed May 7, 2020).

584 Ohdachi S, Aoi T. 1987. Food habits of brown bears in Hokkaido, Japan. Bears: Their Biology

$585 \quad$ and Management 7:215-220. DOI: 10.2307/3872627.

586 Otto KL, Ferguson JD, Fox DG, Sniffen CJ. 1991. Relationship between body condition score

587 and composition of ninth to eleventh rib tissue in Holstein dairy cows. Journal of Dairy

$588 \quad$ Science 74:852-859. DOI: 10.3168/jds.S0022-0302(91)78234-9.

589 Peig J, Green AJ. 2009. New perspectives for estimating body condition from mass/length data:

590 The scaled mass index as an alternative method. Oikos 118:1883-1891. DOI:

$591 \quad 10.1111 / \mathrm{j} .1600-0706.2009 .17643 . x$. 
592 Perryman WL, Lynn MS. 2002. Evaluation of nutritive condition and reproductive status of 593 migrating gray whales (Eschrichtius robustus) based on analysis of photogrammetric data. 594 Journal of Cetacean Research and Management 4:155-164.

595 R Core Team. 2019.R: a language and environment for statistical computing. R Foundation for 596 Statistical Computing, Vienna, Austria. Available at https://www.r-project.org/ (accessed $597 \quad$ May 7, 2020).

598 Samson C, Huot J. 1995. Reproductive biology of female black bears in relation to body mass in 599 early winter. Journal of Mammalogy 76:68-77. DOI: 10.2307/1382315.

600 Sato Y, Itoh T, Mori Y, Satoh Y, Mano T. 2011. Dispersal of male bears into peripheral habitats 601 inferred from mtDNA haplotypes. Ursus 22:120-132. DOI: 10.2192/URSUS-D-10$602 \quad 00037.1$.

603 Sato Y, Mano T, Takatsuki S. 2005. Stomach contents of brown bears Ursus arctos in Hokkaido, $604 \quad$ Japan. Wildlife Biology 11:133-144. DOI: 10.2981/0909-

605 6396(2005)11[133:SCOBBU]2.0.CO;2.

606 Schneider CA, Rasband WS, Eliceiri KW. 2012. NIH Image to ImageJ: 25 years of image $607 \quad$ analysis. Nature Methods 9:671-675. DOI: 10.1038/nmeth.2089.

608 Schulte-Hostedde AI, Millar JS, Hickling GJ. 2001. Evaluating body condition in small 609 mammals. Canadian Journal of Zoology 79:1021-1029. DOI: 10.1139/z01-073.

610 Shimozuru M, Yamanaka M, Nakanishi M, Moriwaki J, Mori F, Tsujino M, Shirane Y,

611 Ishinazaka T, Kasai S, Nose T, Masuda Y, Tsubota T. 2017. Reproductive parameters and 612 cub survival of brown bears in the Rusha area of the Shiretoko Peninsula, Hokkaido, Japan. 613 PLOS ONE 12:e0176251. DOI: 10.1371/journal.pone.0176251. 
614 Shirane Y, Shimozuru M, Yamanaka M, Tsuruga H, Hirano S, Nagano N, Moriwaki J,

615 Nakanishi M, Ishinazaka T, Nose T, Kasai S, Shirayanagi M, Masuda Y, Fujimoto Y,

616 Osada M, Akaishi M, Mano T, Masuda R, Sashika M, Tsubota T. 2018. Sex-biased natal

617 dispersal in Hokkaido brown bears revealed through mitochondrial DNA analysis.

618 European Journal of Wildlife Research 64:65. DOI: 10.1007/s10344-018-1222-x.

619 Stirling I, Thiemann GW, Richardson E. 2008. Quantitative support for a subjective fatness

620 index for immobilized polar bears. Journal of Wildlife Management 72:568-574. DOI:

$621 \quad 10.2193 / 2007-123$.

622 Tukey J. 1977. Exploratory data analysis. Addison-Wesley Publishing Co., Reading.

623 Wildman EE, Jones GM, Wagner PE, Boman RL, Troutt Jr HF, Lesch TN. 1982. A Dairy Cow

624 Body Condition Scoring System and Its Relationship to Selected Production Characteristics.

625 Journal of Dairy Science 65:495-501. DOI: 10.3168/jds.S0022-0302(82)82223-6.

626 Yamanaka M, Aoi T. 1988. Brown bears. In: Ohtaishi N, Nakagawa H eds. Animals of Shiretoko.

627 Sapporo: Hokkaido University Press, 181-223 (in Japanese).

628 Yoneda M. 1976. Age determination and age structure of the Ezo brown bear. The Journal of the

629 Mammalogical Society of Japan 7:1-8. DOI: 10.11238/jmammsocjapan1952.7.1.

630 Young RA. 1976. Fat, energy and mammalian survival. American Zoologist 16:699-710. DOI:

$631 \quad 10.1093 / \mathrm{icb} / 16.4 .699$.

632

633 


\section{Figure 1}

Map of the Shiretoko Peninsula, Hokkaido, Japan.

The dotted line indicates the Shiretoko National Park. This map was created using QGIS version 2.16 (QGIS Development Team, 2017. QGIS Geographic Information System. Open Source Geospatial Foundation Project. http://ggis.osgeo.org) and edited by the author. The base-map image, contour lines, topographic features are based on the National Land Numerical Information published by National Spatial Planning and Regional Policy Bureau, Ministry of Land, Infrastructure, Transport, and Tourism of Japan (available from http://nlftp.mlit.go.jp/ksj/index.html, accessed 7 December 2017).

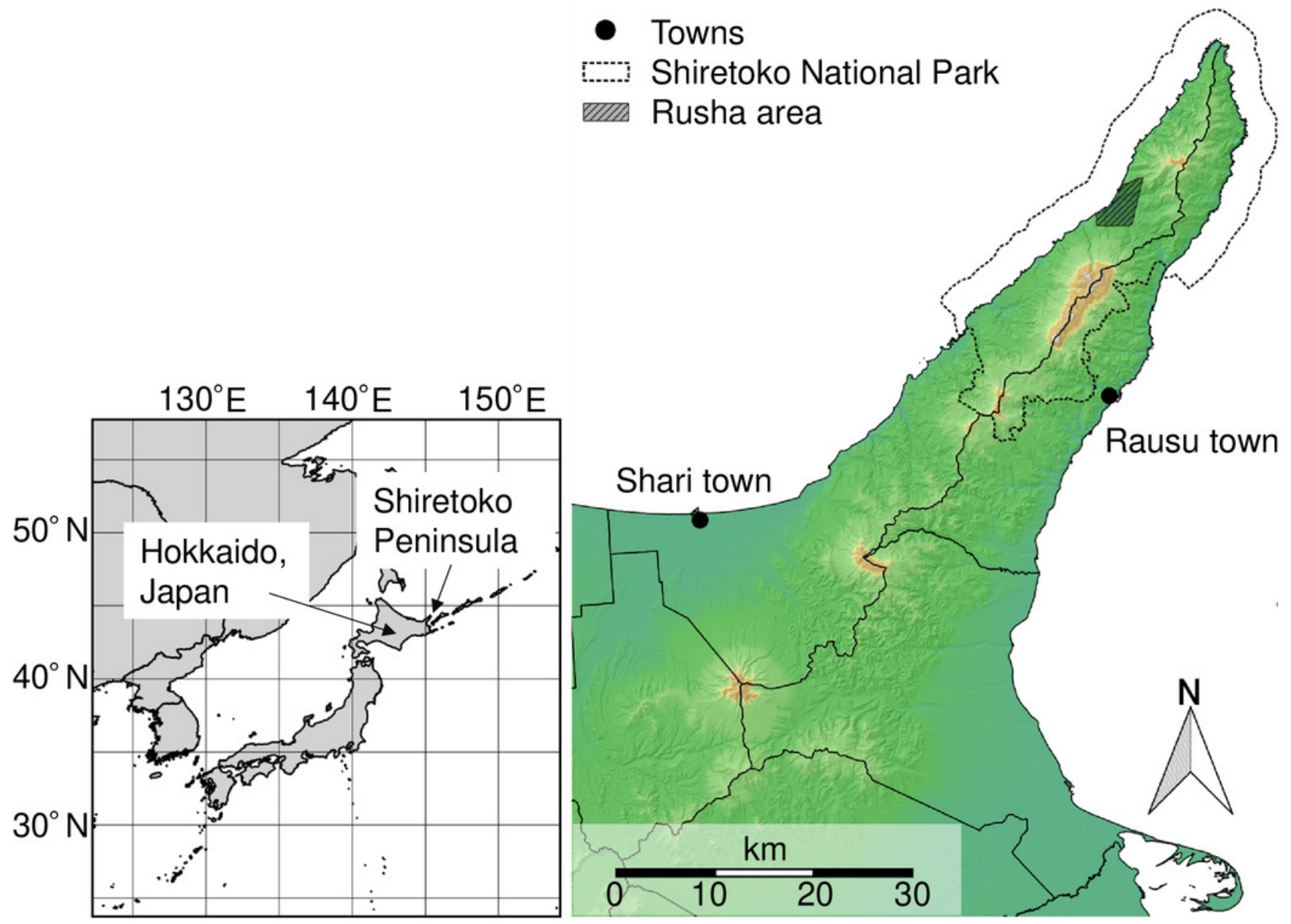


Figure 2

Four candidate methods of measurement to evaluate the body condition of brown bears in the Shiretoko Peninsula, Hokkaido, Japan.

(A) Horizontal body length (HBL). (B) Euclidean body length (EBL). (C) Polygonal-line body length (PBL). (D) Horizontal torso length (HTL). Photo credit: Yuri Shirane

A. Horizontal Body Length (HBL)

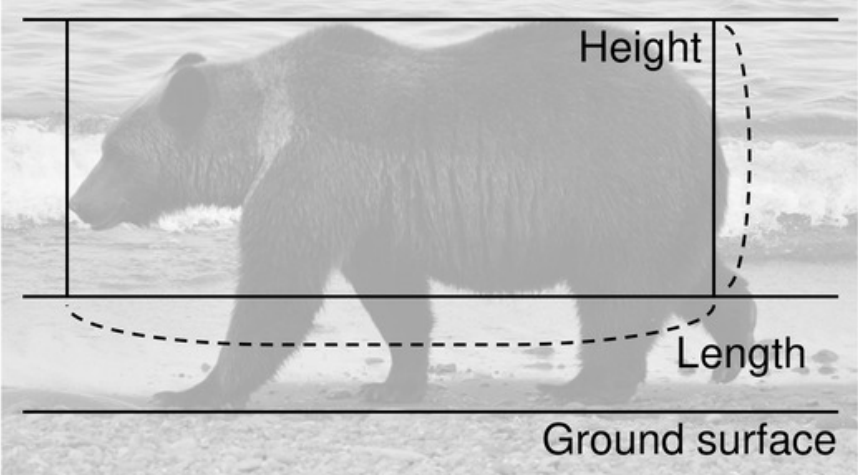

C. Polygonal-line Body Length (PBL)

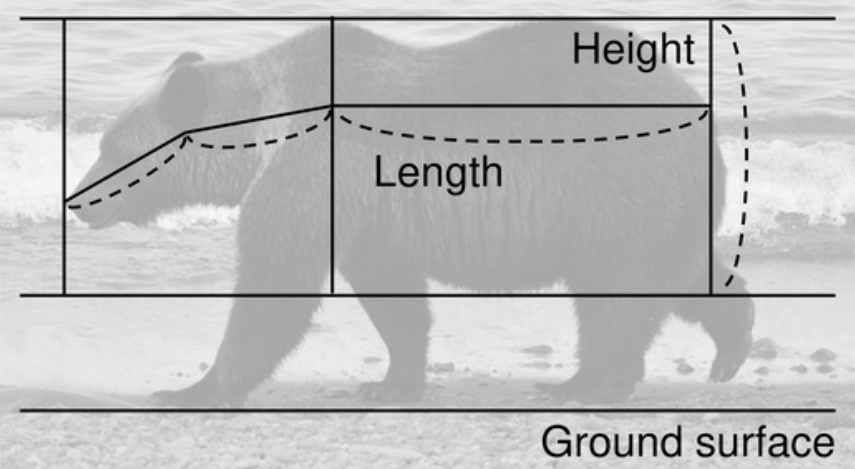

B. Euclidean Body Length (EBL)

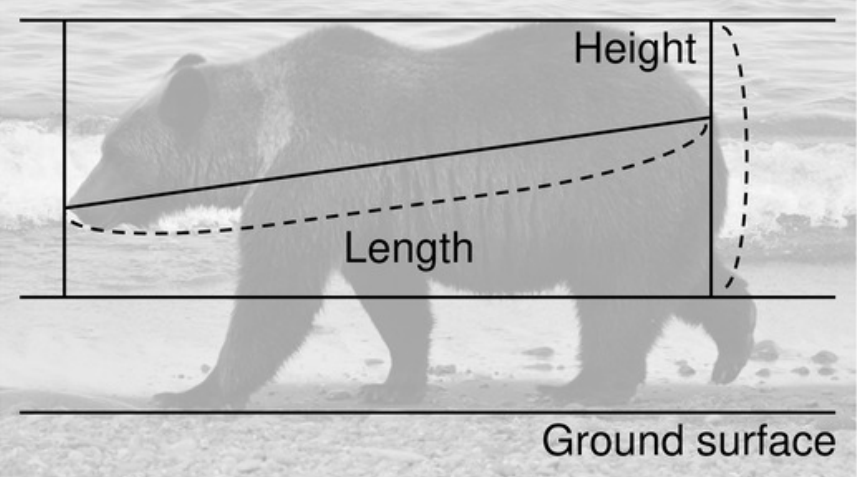

D. Horizontal Torso Length (HTL)

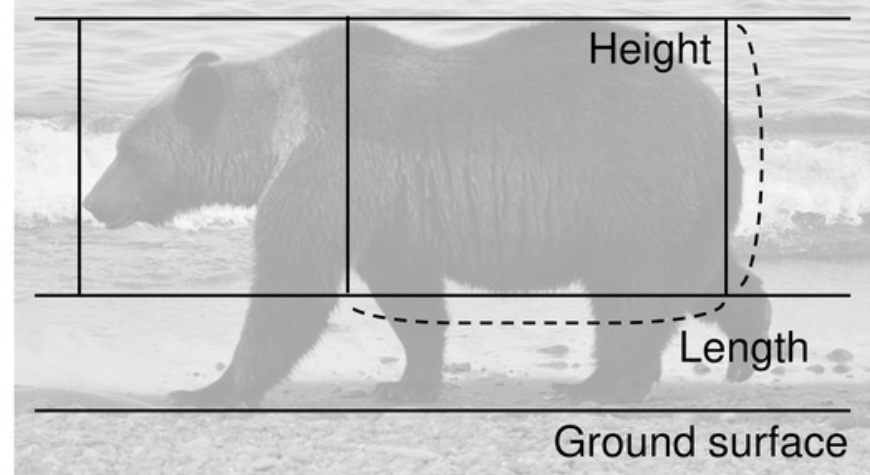


Figure 3

Body length at age for 174 female $(O)$ and 258 male (0) brown bears in the Shiretoko Peninsula, Hokkaido, Japan.

Fitted lines represent the von Bertalanffy growth curve for females (dashed line) and males (solid line).

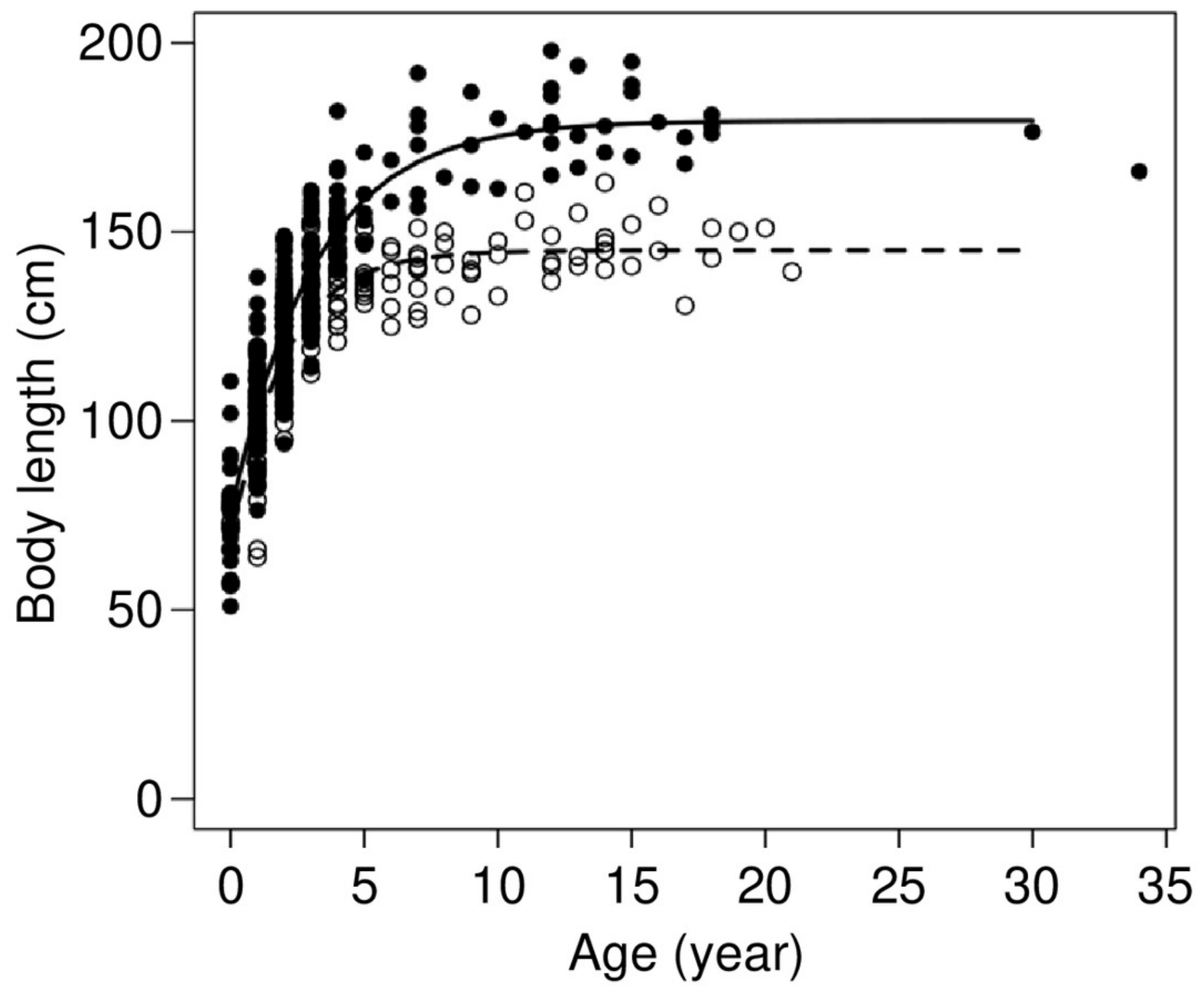


Figure 4

Relationship between In-transformed body weight and In-transformed body length for 476 brown bears killed or captured in the Shiretoko Peninsula, Hokkaido, Japan, during 1998-2017.

The solid line indicates the best fitting line determined by ordinary least squares regression and is described as follows: In body weight $=3.04 \cdot$ In body length $-10.41\left(R^{2}=0.94\right.$, residual standard deviation $=0.19$ ). 


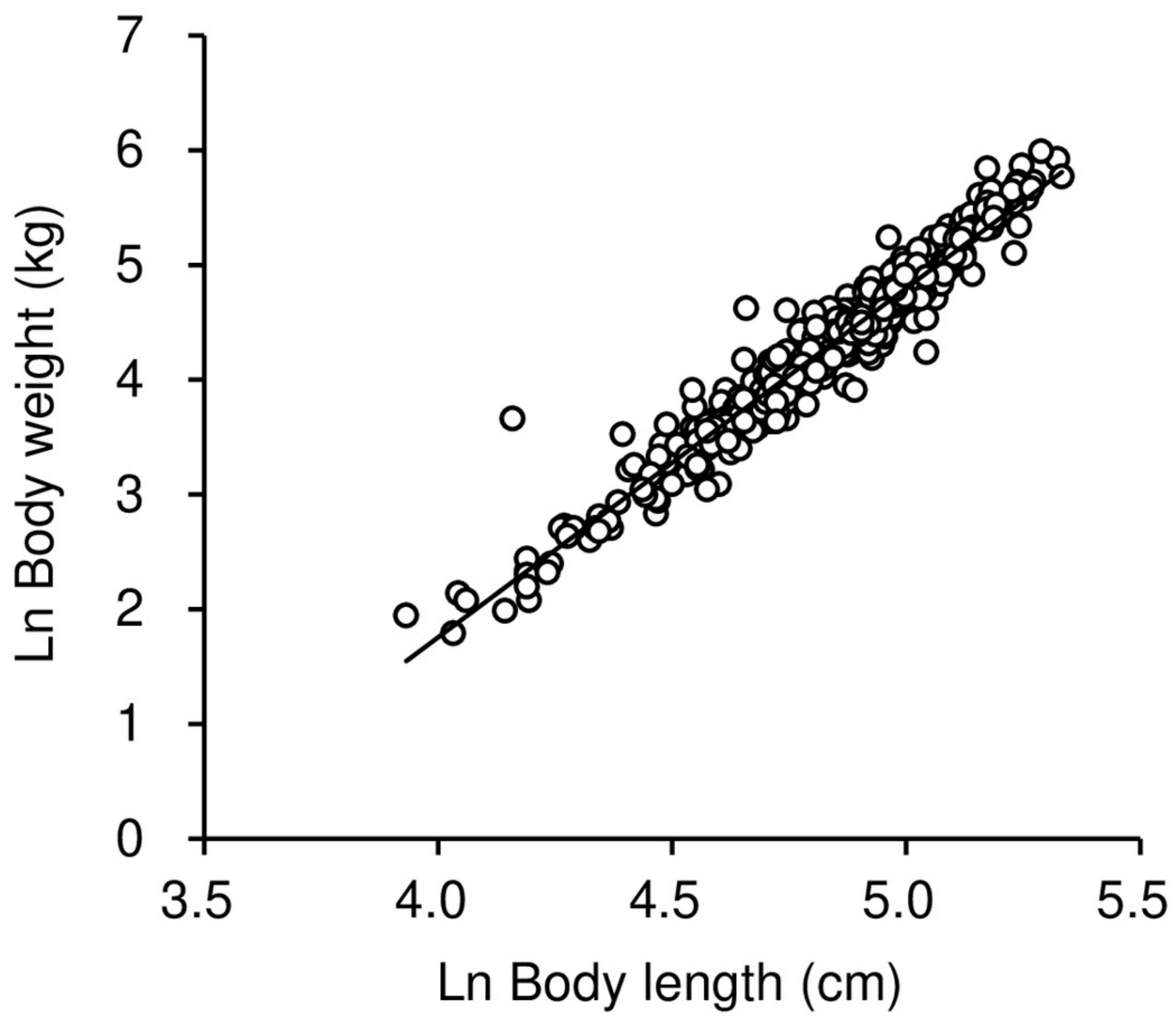


Figure 5

Monthly mean body condition index $(\mathrm{BCl})$ of 476 brown bears killed or captured in the Shiretoko Peninsula, Hokkaido, Japan, during 1998-2017.

Error bars show SEs.

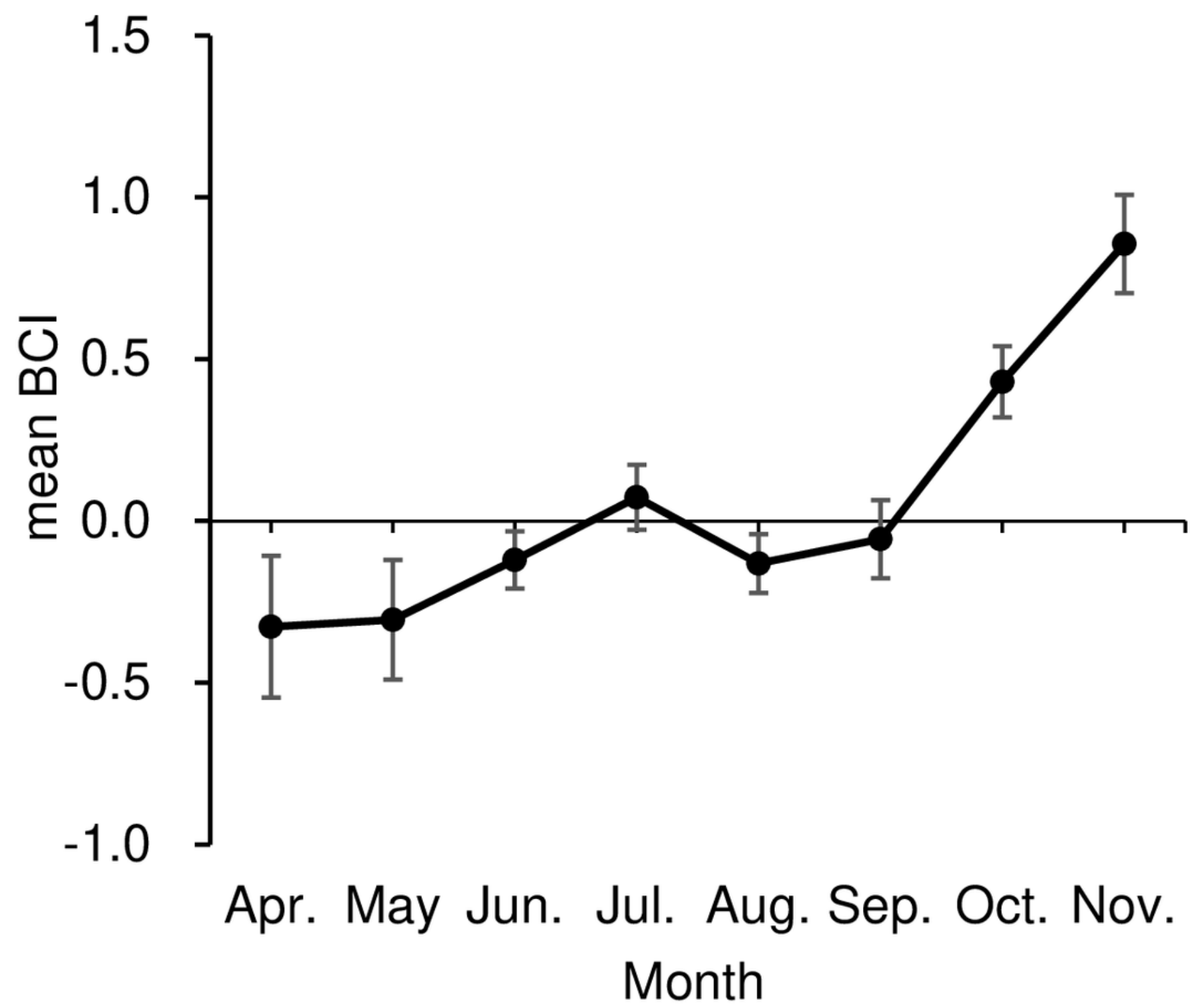


Figure 6

Relationship between torso height:body length ratio ( $\mathrm{TH}: \mathrm{BL})$ and body condition index $(\mathrm{BCl})$ for 23 adult female brown bears killed or captured in the Shiretoko Peninsula, Hokkaido, during 2014-2017.

Pearson's correlation was $r=0.81\left(R^{2}=0.65, p<0.001\right)$.

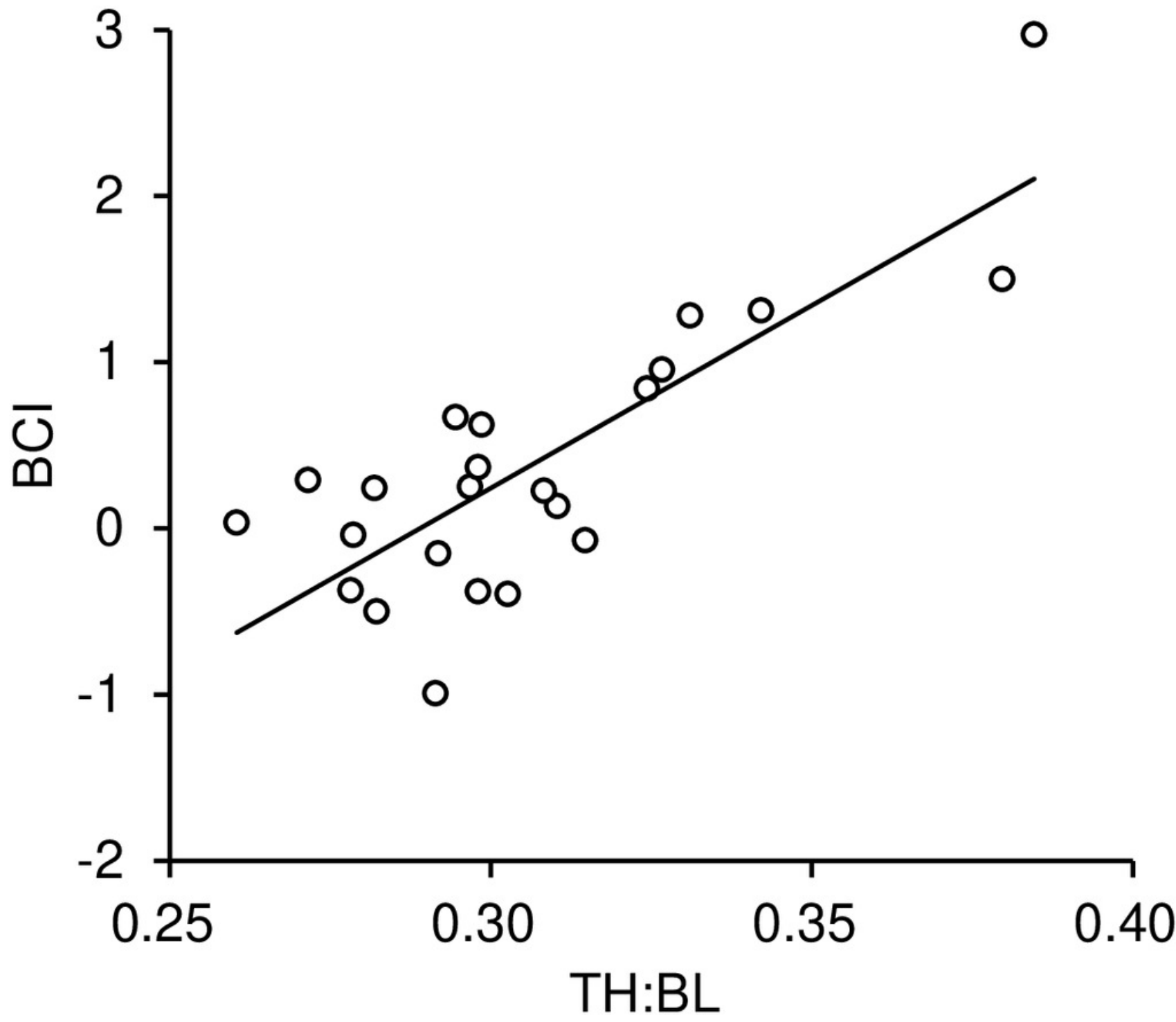


Figure 7

Seasonal changes in body condition estimated by calculating torso height:length ratio (TH:HTL) from photographs of an adult female brown bear in the Rusha area of the Shiretoko Peninsula, 2016-2018.

TH:HTL was compared among half-months by one-way ANOVA with a post hoc Tukey multiple comparison test. Same letters indicate significant differences. Error bars show SEs.

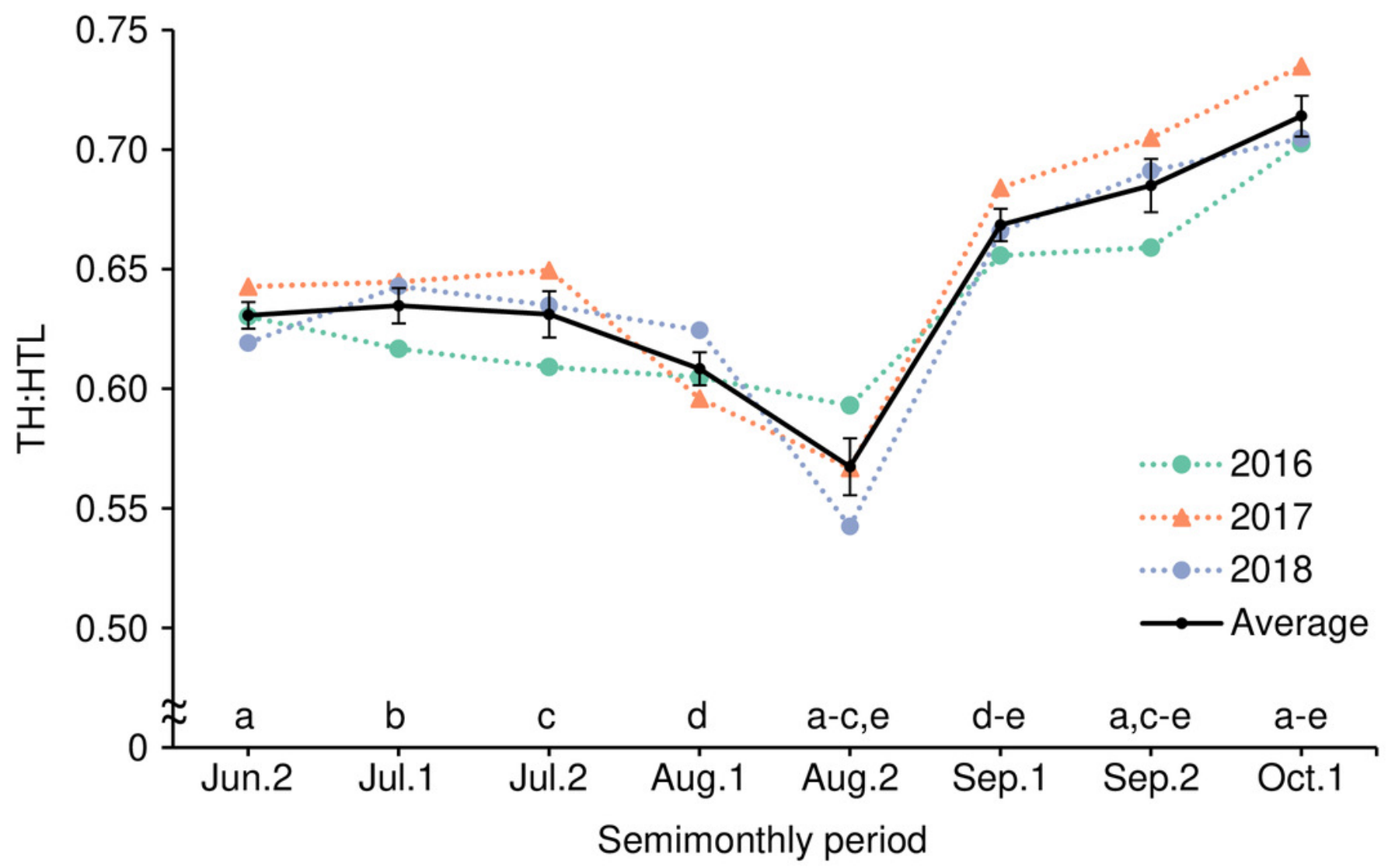


Figure 8

Relationship between torso height:length ratio (TH:HTL) and body condition index $(\mathrm{BCl})$ for seven adult female brown bears captured in the Rusha area of the Shiretoko Peninsula, Hokkaido, 2014-2016.

Pearson's correlation was $r=0.77\left(\mathrm{R}^{2}=0.59, p=0.042\right)$.

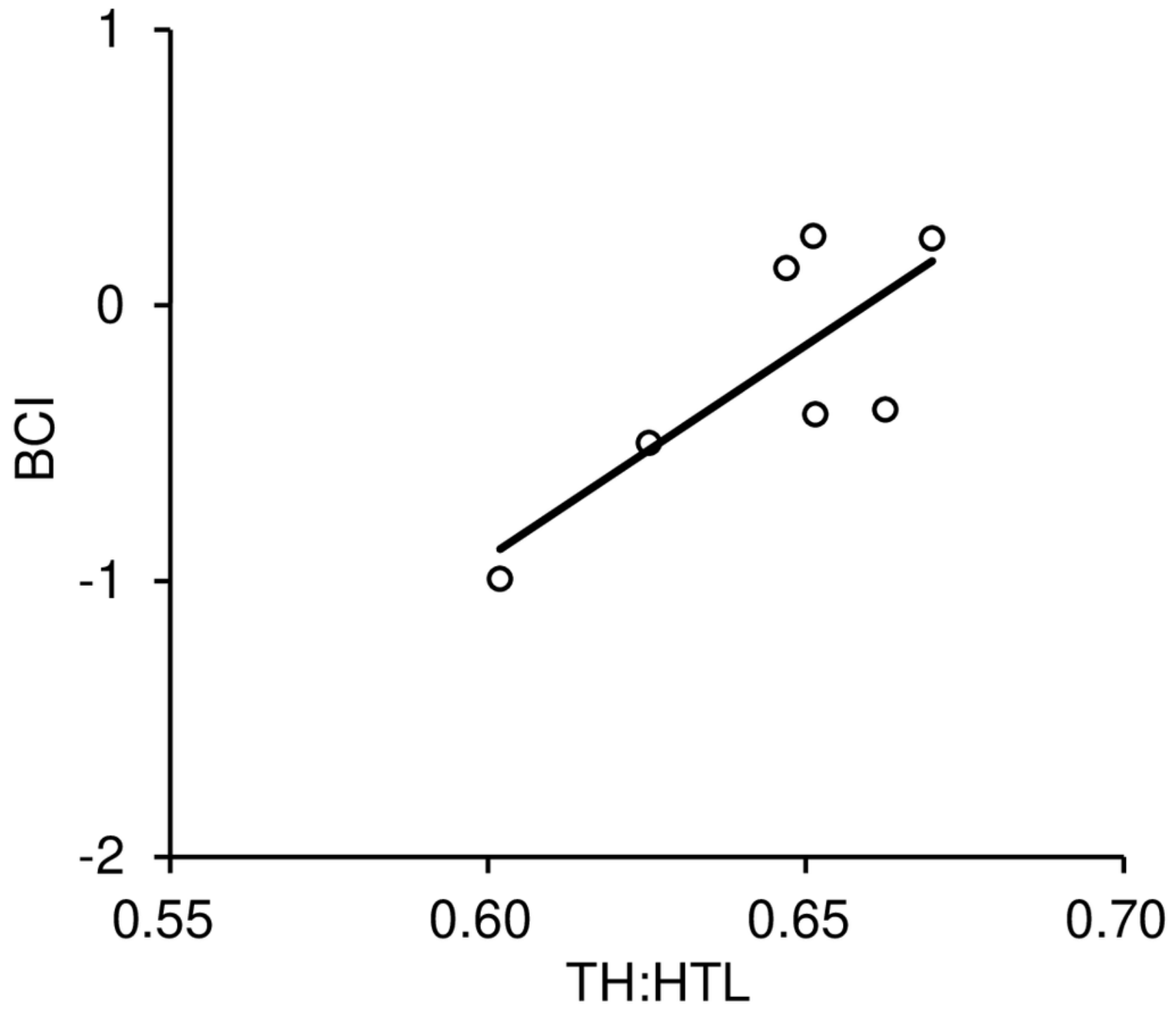




\section{Table $\mathbf{1}$ (on next page)}

Parameter estimates $( \pm \mathrm{SE}$ ) for von Bertalanffy size-at-age curves for the body lengths of 432 brown bears in the Shiretoko Peninsula, Hokkaido, Japan.

$A_{\infty}$ is the asymptotic body length, $K$ is the size growth constant, and $T$ is the theoretical age at which the animal would have size 0 . 


\section{Table 1:}

2 Parameter estimates $( \pm \mathrm{SE})$ for von Bertalanffy size-at-age curves for the body lengths of 432

3 brown bears in the Shiretoko Peninsula, Hokkaido, Japan.

$4 \mathrm{~A}_{\infty}$ is the asymptotic body length, $\mathrm{K}$ is the size growth constant, and $\mathrm{T}$ is the theoretical age at 5 which the animal would have size 0.

6

\begin{tabular}{lcccc}
\hline Sex & $\mathrm{A}_{\infty}(\mathrm{cm})$ & $\mathrm{K}\left(\right.$ year $\left.^{-1}\right)$ & $\mathrm{T}($ years $)$ & $n$ \\
\hline Female & $145.07 \pm 1.48$ & $0.51 \pm 0.04$ & $-1.28 \pm 0.16$ & 174 \\
Male & $179.47 \pm 2.39$ & $0.32 \pm 0.02$ & $-1.73 \pm 0.14$ & 257 \\
\hline
\end{tabular}

7

8 


\section{Table 2 (on next page)}

Mean body condition index $(\mathrm{BCl})$ and body weight of brown bears in six age-sex classes captured and measured in the Shiretoko Peninsula, Hokkaido, Japan, during 1998-2017.

Spring is April-June, summer is July and August, and autumn is September-November. 
Table 2:

2 Mean body condition index (BCI) and body weight of brown bears in six age-sex classes 3 captured and measured in the Shiretoko Peninsula, Hokkaido, Japan, during 1998-2017.

4 Spring is April-June, summer is July and August, and autumn is September-November.

5

6

\begin{tabular}{|c|c|c|c|c|c|c|c|c|c|}
\hline \multirow[b]{2}{*}{ Class } & \multicolumn{3}{|c|}{ Spring } & \multicolumn{3}{|c|}{ Summer } & \multicolumn{3}{|c|}{ Autumn } \\
\hline & $\mathrm{BCI}$ & $\begin{array}{l}\text { Weight } \\
(\mathrm{kg})\end{array}$ & $n$ & $\mathrm{BCI}$ & $\begin{array}{l}\text { Weigh } \\
\mathrm{t}(\mathrm{kg})\end{array}$ & $n$ & $\mathrm{BCI}$ & $\begin{array}{l}\text { Weight } \\
(\mathrm{kg})\end{array}$ & $n$ \\
\hline
\end{tabular}

Female

Adult

$$
\begin{array}{ll}
-0.39 \pm & 98.5 \pm 14 \\
0.26 & 4.8
\end{array}
$$$$
-0.18 \pm 101.4 \quad 35
$$$$
0.20 \pm 116.2 \pm 43
$$$$
0.12 \pm 3.6
$$

0.14

4.1

Subadult

$$
-0.39 \pm 61.9 \pm 27
$$$$
-0.20 \pm 53.3 \pm 46
$$$$
0.17 \pm 72.5 \pm 32
$$

$$
0.13 \quad 5.4
$$

0.21

4.1

$0.16 \quad 6.2$

Cub

- $\quad$ - 0

$0.36 \pm 10.8 \pm 3$

$-0.08 \quad 16.1 \pm 5$

0.48

1.7

$\pm 0.25 \quad 0.7$

Male

Adult

$$
0.63 \pm 230.1 \pm 4
$$$$
0.37 \pm 213.4 \quad 24
$$$$
1.16 \pm 309.2 \pm 13
$$$$
0.35
$$

$0.14 \pm 7.2$

0.19

13.2

Subadult $\quad-0.15 \pm 78.8 \pm 77$

$-0.01 \pm 85.2 \pm 91$

$0.51 \pm 99.7 \pm 43$

$0.12 \quad 4.0$

$0.08 \quad 5.5$

$\mathrm{Cub}$

$$
\begin{array}{ll}
-0.30 \pm & 6.0 \\
0.00 & 0.0
\end{array}
$$

$0.12 \pm 11.5 \pm 6$

$0.14 \quad 6.6$

0.45

1.6

$0.16 \pm 22.4 \pm 12$

$0.33 \quad 4.3$

\begin{tabular}{llllllllll} 
All classes & $-0.20 \pm$ & 81.7 & \pm & 12 & $-0.03 \pm$ & 92.5 & \pm 205 & $0.36 \pm$ & $107.9 \pm 148$ \\
pooled & 0.00 & 0.1 & 3 & 0.00 & 0.1 & & 0.00 & 0.1 & \\
\hline
\end{tabular}




\section{Table 3 (on next page)}

Measurement precision within photographs of an adult female brown bear (bear-ID: HC) in the Rusha area of the Shiretoko Peninsula, Hokkaido, Japan.

The standard error (SE) in the ratio of torso height to body/torso length at a certain number of measurements was calculated by considering the standard deviation (SD) obtained from 50 times measurements as the population standard deviation. CV means coefficient of variation. 


\section{Table 3:}

2 Measurement precision within photographs of an adult female brown bear (bear-ID: HC) in 3 the Rusha area of the Shiretoko Peninsula, Hokkaido, Japan.

4 The standard error (SE) in the ratio of torso height to body/torso length at a certain number of 5 measurements was calculated by considering the standard deviation (SD) obtained from 50 times 6 measurements as the population standard deviation. CV means coefficient of variation.

7

\begin{tabular}{|c|c|c|c|c|c|}
\hline \multirow[b]{2}{*}{ Methods } & \multicolumn{2}{|c|}{50 measurements } & \multicolumn{3}{|c|}{ SE (number of measurement) } \\
\hline & mean $\pm \mathrm{SD}$ & $\mathrm{CV}$ & (two) & (three) & (four) \\
\hline TH:HBL & $0.4316 \pm 0.0016$ & $0.36 \%$ & 0.0011 & 0.0009 & 0.0008 \\
\hline TH:EBL & $0.4266 \pm 0.0015$ & $0.35 \%$ & 0.0010 & 0.0009 & 0.0007 \\
\hline TH:PBL & $0.4163 \pm 0.0015$ & $0.35 \%$ & 0.0010 & 0.0009 & 0.0007 \\
\hline TH:HTL & $0.7504 \pm 0.0040$ & $0.53 \%$ & 0.0028 & 0.0023 & 0.0020 \\
\hline
\end{tabular}

8 TH: torso height

9 HBL: horizontal body length

10 EBL: Euclidean body length

11 PBL: polygonal line body length

12 HTL: horizontal torso length. 


\section{Table 4 (on next page)}

Mean ( $\pm \mathrm{SD}$ ) ratio of torso height to body/torso length obtained from photographs of an adult female brown bear (bear-ID: HC) in the Rusha area of the Shiretoko Peninsula, Hokkaido, Japan.

$P$ values are based on comparisons of mean ratios from the "Good" category versus other categories for each measurement method with Tukey multiple comparisons. Bold characters indicate significant differences. The "Good" category contained photographs with a score of 1 for all attributes, "BS" had a score of 2 for body straightness only, "NF" had a score of 2 for neck flexing only, and "NB" had a score of 2 for neck lateral bending only. 


\section{Table 4:}

2 Mean ( \pm SD) ratio of torso height to body/torso length obtained from photographs of an adult female brown bear (bear-ID: HC) 3 in the Rusha area of the Shiretoko Peninsula, Hokkaido, Japan.

$4 P$ values are based on comparisons of mean ratios from the "Good" category versus other categories for each measurement method with 5 Tukey multiple comparisons. Bold characters indicate significant differences. The "Good" category contained photographs with a score 6 of 1 for all attributes, "BS" had a score of 2 for body straightness only, "NF" had a score of 2 for neck flexing only, and "NB" had a 7 score of 2 for neck lateral bending only.

\begin{tabular}{|c|c|c|c|c|c|c|c|c|c|c|c|c|c|}
\hline & & TH:HBL & & & TH:EBL & & & TH:PBL & & & TH:HTL & & \\
\hline $\begin{array}{l}\text { Categ } \\
\text { ories }\end{array}$ & $n$ & $\begin{array}{l}\text { mean } \pm \\
\text { SD }\end{array}$ & $\mathrm{CV}$ & $p$-value & $\begin{array}{l}\text { mean } \pm \\
\mathrm{SD}\end{array}$ & $\mathrm{CV}$ & $p$-value & $\begin{array}{l}\text { mean } \pm \\
\mathrm{SD}\end{array}$ & $\mathrm{CV}$ & $p$-value & $\begin{array}{l}\text { mean } \pm \\
\mathrm{SD}\end{array}$ & $\mathrm{CV}$ & $p$-value \\
\hline Good & 15 & $\begin{array}{l}0.416 \pm \\
0.010\end{array}$ & $\begin{array}{l}2.47 \\
\%\end{array}$ & & $\begin{array}{l}0.409 \pm \\
0.009\end{array}$ & $\begin{array}{l}2.19 \\
\%\end{array}$ & & $\begin{array}{l}0.394 \pm \\
0.011\end{array}$ & $\begin{array}{l}2.88 \\
\% \\
\end{array}$ & & $\begin{array}{l}0.711 \pm \\
0.025\end{array}$ & $\begin{array}{l}3.45 \\
\%\end{array}$ & \\
\hline BS & 9 & $\begin{array}{l}0.454 \pm \\
0.020\end{array}$ & $\begin{array}{l}4.34 \\
\% \\
\end{array}$ & $<0.001$ & $\begin{array}{l}0.431 \pm \\
0.017\end{array}$ & $\begin{array}{l}4.00 \\
\%\end{array}$ & 0.003 & $\begin{array}{l}0.413 \pm \\
0.015\end{array}$ & $\begin{array}{l}3.60 \\
\% \\
\end{array}$ & 0.010 & $\begin{array}{l}0.762 \pm \\
0.034\end{array}$ & $\begin{array}{l}4.46 \\
\%\end{array}$ & 0.001 \\
\hline NF & 10 & $\begin{array}{l}0.444 \pm \\
0.015\end{array}$ & $\begin{array}{l}3.38 \\
\% \\
\end{array}$ & $<0.001$ & $\begin{array}{l}0.428 \pm \\
0.014\end{array}$ & $\begin{array}{l}3.18 \\
\%\end{array}$ & 0.009 & $\begin{array}{l}0.401 \quad \pm \\
0.013\end{array}$ & $\begin{array}{l}3.29 \\
\% \\
\end{array}$ & 0.586 & $\begin{array}{l}0.721 \pm \\
0.028\end{array}$ & $\begin{array}{l}3.86 \\
\% \\
\end{array}$ & 0.836 \\
\hline NB & 9 & $\begin{array}{l}0.435 \pm \\
0.014\end{array}$ & $\begin{array}{l}3.17 \\
\%\end{array}$ & 0.028 & $\begin{array}{l}0.428 \pm \\
0.014\end{array}$ & $\begin{array}{l}3.25 \\
\%\end{array}$ & 0.008 & $\begin{array}{l}0.412 \pm \\
0.014\end{array}$ & $\begin{array}{l}3.29 \\
\%\end{array}$ & 0.023 & $\begin{array}{l}0.736 \pm \\
0.028\end{array}$ & $\begin{array}{l}3.74 \\
\%\end{array}$ & 0.186 \\
\hline
\end{tabular}

9 TH: torso height

10 HBL: horizontal body length

11 EBL: Euclidean body length

12 PBL: polygonal line body length

13 HTL: horizontal torso length. 
